\title{
EFEITO DA DESFOLHA DE RAMOS SOBRE A INDUÇÃO DE BROTOS E FLORES EM ATEMÓIA (Anonna cherimola Mill x Anonna squamosa L.) ${ }^{1}$
}

\author{
EURICO EDUARDO PINTO DE LEMOS², GUSTAVO DE ALBUQUERQUE MARINHO ${ }^{3}$, MAXIMILI COSTA ALMEIDA³
}

\begin{abstract}
RESUMO - Avaliou-se o efeito do desfolhamento de ramos na produção de brotos e flores em plantas adultas de atemóia (Anonna cherimola Mill x Anonna squamosa L.) var. Gefner. O experimento foi realizado em plantio comercial no município de Maceió - AL. Foram utilizadas 24 plantas podadas com altura de $1.5 \mathrm{~m}$ e espaçadas de 4 x $2 \mathrm{~m}$. Os ramos maduros tiveram seus ápices removidos na altura da $4^{\mathrm{a}}$ folha, sendo depois submetidos aos seguintes tratamentos de desfolha manual: 1) desfolha total dos ramos; 2) remoção das cinco primeiras folhas dos ramos a partir dos ápices podados; 3) remoção de cinco folhas compreendidas entre $6^{\mathrm{a}}$ a $10^{\mathrm{a}}$ gemas dos ramos; 4) controle = sem desfolha dos ramos. Os resultados coletados 30 dias após a desfolha mostraram que o número de brotações nos tratamentos com desfolha total e desfolha das cinco gemas superiores foi estatisticamente superior aos tratamentos sem desfolha e desfolha da $6^{\mathrm{a}}$ à $10^{\mathrm{a}}$ gema. O tratamento com desfolha das cinco gemas superiores apresentou o maior número de ramos florados $(61 \%)$.
\end{abstract}

Termos para indexação: anonácea, brotação, floração, produção na entressafra.

\section{EFFECTS OF LEAF REMOVAL OF ATEMOYA BRANCHES (Anonna cherimola Mill x Anonna squamosa L.) ON SHOOT AND FLOWER FORMATION}

\begin{abstract}
The effects of leaf removal from selected sections of atemoya branches var. Gefner on shoot and flower formation were evaluated. The experiment was carried out in a commercial orchard in Maceió, State of Alagoas, Brazil. Twenty four adult plants pruned to $1.5 \mathrm{~m}$ height with a 4 x $2 \mathrm{~m}$ spacing were used. All mature lignified branches had their tip pruned up to the $4^{\text {th }}$ leaf. After pruning the following treatments were applied: 1) total leaf removal from the branches; 2) removal of the first five leaves counted from the pruned tip; 3 ) removal of the five leaves between the $6^{\text {th }}$ and $10^{\text {th }}$ buds of the branches; 4) Control = no leaf removal. The results obtained at 30 days after leaf removal showed that the number of new shoots was statistically superior in the treatments with total leaf removal and removal of the first five leaves in relation to the two other treatments studied. The treatment with the removal of the first five leaves presented the highest number of branches with flowers $(61 \%)$.
\end{abstract}

Index terms: flowering, custard apple, leaf abscission, flowering control.

A atemóia, híbrido interespecífico de Anonna cherimola Mill x Anonna squamosa L., é cultivada principalmente nas regiões Sul e Sudeste do Brasil. Recentemente, a atemóia var. Gefner foi introduzida com sucesso no Nordeste, nos projetos de irrigação do Vale do São Francisco (São José, 1997). Segundo Donadio (1997), por sua maior versatilidade e maior adaptação às condições tropicais e subtropicais em relação à cherimóia, a produção de atemóia tende a crescer no Brasil.

O controle da floração de fruteiras é uma ferramenta importante para regular o mercado e proporcionar melhores preços aos produtores. $\mathrm{Na}$ atemóia, assim como na pinheira (Annona squamosa L.), as gemas vegetativas estão situadas abaixo do pecíolo foliar e, para brotarem, é necessário que as folhas caiam ou sejam removidas (Bonaventure, 1999). As flores das plantas de pinha e de atemóia surgem sempre a partir das novas brotações vegetativas e podem ser estimuladas ou inibidas controlando-se a poda e a desfolha dos ramos (Lemos \& Marinho, 1999). Kavati \& Piza Jr. (1997) recomendaram, para as condições de cultivo de São Paulo, o emprego da poda de verão em operação conjunta com a desfolha, nos meses de janeiro a março. Os autores relataram que podas realizadas antes do mês de janeiro permitem a produção de frutos quando os preços ainda estão baixos.

Este trabalho teve como objetivo avaliar o efeito da desfolha, associada à desponta do ramo na produção de brotos e flores de atemóia var. Gefner, nas condições dos Tabuleiros Costeiros do Nordeste Brasileiro.

O experimento foi realizado com plantas de atemóia cultivadas irrigado na Chácara das Anonáceas, localizada no município de MaceióAL, no período de fevereiro a abril de 2000 . Foram utilizadas 24 plantas sadias de atemóia da variedade Gefner com três anos de idade, propagadas por enxertia sobre cavalos de pinha, podadas à altura de $1,5 \mathrm{~m} \mathrm{e}$ espaçadas de $4 \times 2 \mathrm{~m}$. Os ramos maduros (lignificados ou semilignificados) tiveram seus ápices removidos na altura da $4^{a}$ folha. Em seguida, aplicaram-se os seguintes tratamentos de desfolha manual: 1) desfolha total dos ramos; 2) remoção das cinco primeiras folhas dos ramos a partir dos em solo Podzólico Vermelho-Amarelo Distrófico de um pomar comercial

ápices podados; 3 ) remoção de cinco folhas compreendidas entre a $6^{\mathrm{a}} \mathrm{e}$ a $10^{\mathrm{a}}$ gemas dos ramos; 4) controle $=$ sem desfolha dos ramos. $\mathrm{O}$ delineamento experimental foi o inteiramente ao acaso, com seis repetições, sendo cada unidade experimental constituída por uma planta. As médias dos tratamentos foram comparadas pelo teste de Tukey, ao nível de 5\% de probabilidade.

Os dados foram coletados aos 30 dias após a execução dos tratamentos. As variáveis observadas foram: número de gemas brotadas por ramo e número de gemas com flores por ramo.

Os resultados obtidos indicaram variações estatisticamente significativas entre os tratamentos (Tabela 1). Nos tratamentos desfolha total e desfolha das gemas superiores, o início das brotações aconteceu cerca de uma semana após a remoção das folhas, mantendo-se um número constante de brotações ao longo dos 30 dias do experimento. Para os ramos que sofreram a desfolha total, apesar da maior quantidade de gemas intumescidas ( $>10)$, observou-se que apenas 4,88 gemas em média, localizadas próximas ao ápice do ramo, efetivamente brotaram, não diferindo estatisticamente do tratamento em que se removeram apenas as cinco primeiras folhas do ápice (média de 4,08 gemas brotadas).

TABELA 1-Número de brotações em ramos de atemóia obtidos aos 30 após tratamentos de desfolha e desponta. Maceió-AL, 2000. Média de 6 repetições por tratamento.

\begin{tabular}{lcc}
\hline Tratamento do Ramo & \multicolumn{2}{c}{ Número de Brotos/Ramo } \\
\cline { 2 - 3 } & Dados originais & Dados transformados \\
\hline Desfolha Total & 4,88 & $2,42 \mathrm{a}$ \\
$\begin{array}{l}\text { Desfolha das 5 gemas } \\
\text { superiores }\end{array}$ & 4,08 & $2,24 \mathrm{a}$ \\
$\begin{array}{l}\text { Desfolha da 6a à } 10^{\mathrm{a}} \\
\text { gema }\end{array}$ & 1,08 & $1,39 \mathrm{~b}$ \\
Sem Desfolha & 0,00 & $1,00 \mathrm{c}$ \\
\hline C.V. & 11,18 \\
\hline $\begin{array}{l}\text { Médias seguidas da mesma letra não diferem entre si, pelo teste de Tukey, a 5\% de } \\
\text { probabilidade. Dados foram transformados em } \sqrt{\mathrm{x}+1 .}\end{array}$
\end{tabular}

\footnotetext{
'(Trabalho 003/2002). Recebido: 10/01/2002. Aceito para publicação: 28/02/2003

2 Eng. Agr. Ph.D. Professor Adjunto. Centro de Ciências Agrárias. Universidade Federal de Alagoas. BR 104 Norte, Km 14, 57072-970, Maceió - AL. Email: eepl@ceca.ufal.br

${ }^{3}$ Mestrando em Agronomia - Produção Vegetal. CECA-UFAL, Maceió - AL. CEP 57072-970.
} 
Os ramos com as folhas intermediárias removidas tiveram uma média de apenas 1,08 gema brotada até o final do experimento. Já nos ramos sem desfolha, não ocorreu nenhuma brotação no período observado, demonstrando ser necessária a remoção das folhas para a liberação das gemas dormentes sob os pecíolos.

Cautin \& Razeto (1999), avaliando o comportamento de gemas de cherimóia submetidas a tratamentos de floração forçada, observaram que os tratamentos de desfolha apical com desponta apresentaram maiores porcentagens de brotação em relação aos tratamentos de desfolha total, média e basal. Os autores atribuíram estes resultados à forte dominância apical que a espécie possui, a qual provoca um escalonamento desde os setores distais até os mais basais do ramo. Por sua vez, Tamas (1990) demonstrou que, em plantas com dominância apical completa, o desenvolvimento da gema é detido em um estágio inicial, e a atividade mitótica é inibida. No entanto, o crescimento da gema lateral é retomado mediante a abscisão da gema apical ou a inativação da sua influência dominante.

No presente trabalho, o tratamento com desfolha total dos ramos evidenciou esta dominância apical em cadeia, pois houve brotações na sua parte superior, mas as gemas inferiores intumesceram, mas não brotaram.

A manutenção das folhas próximo ao ápice inibiu a brotação de gemas liberadas da parte intermediária (entre a $6^{\mathrm{a}} \mathrm{e} 10^{\mathrm{a}}$ folha) dos ramos. Estes resultados demonstram a manutenção da dominância apical exercida pelas folhas produtoras de auxinas no ápice do ramo. Neste tratamento (desfolha da parte mediana do ramo), apenas uma média de 1,08 gema foi liberada, mantendo-se as outras em estado de dormência (Tabela 1).

A produção média de flores/ramo foi de 2,5 no tratamento em que houve a desfolha apenas das cinco primeiras gemas no ápice dos ramos. A média caiu para 1,33 flor/ramo naqueles desfolhados totalmente e 0,58 flores/ramo naqueles com desfolhamento da região mediana (Tabela 2). Este aumento no número de gemas florais no ápice dos ramos sugere que a manutenção de folhas maduras na base do ramo, como fontes de produção de açúcar, garante a iniciação de um maior número de flores. Além disso, a drástica redução no número de brotos com flores, quando se removeram as folhas intermediárias, mostra que a posição da gema é um fator importante no estímulo à brotação e à floração. A dominância relativa de gemas superiores sobre gemas inferiores em anonáceas foi também constatada por Cautin \& Razeto (1999) quando estudaram o comportamento da floração em relação ao desfolhamento de secções de ramos de cherimóia.

Os resultados obtidos neste trabalho mostraram que o controle da indução de flores em atemóia pode ser obtido pela remoção de folhas para a quebra da dormência de gemas vegetativas. A maior quantidade de brotos com flores (máximo de 61\%) foi obtida no tratamento com desfolhamento das primeiras cinco gemas apicais após a desponta dos ramos.
TABELA 2- Número de brotações com flores em ramos de atemóia obtidos aos 30 dias após tratamentos de desfolha e desponta. Maceió-AL,2000. Média de 6 repetições por tratamento.

\begin{tabular}{|c|c|c|}
\hline \multirow[t]{2}{*}{ Tratamento do Ramo } & \multicolumn{2}{|c|}{ Número de Brotos/Ramo } \\
\hline & Dados originais & Dados transformados \\
\hline Desfolha Total & 1,33 & $1,44 a b$ \\
\hline $\begin{array}{l}\text { Desfolha das } 5 \text { gemas } \\
\text { superiores }\end{array}$ & 2,50 & $1,85 \mathrm{a}$ \\
\hline $\begin{array}{l}\text { Desfolha da } 6^{\mathrm{a}} \text { à } 10^{\mathrm{a}} \\
\text { gema }\end{array}$ & 0,58 & $1,24 b$ \\
\hline Sem Desfolha & 0,00 & $1,00 \mathrm{~b}$ \\
\hline C.V. & & 25,05 \\
\hline
\end{tabular}

Médias seguidas da mesma letra não diferem entre si, pelo teste de Tukey, a 5\% de probabilidade. Dados foram transformados em $\sqrt{x}+1$.

\section{REFERÊNCIAS BIBLIOGRÁFICAS}

BONAVENTURE, L. A cultura da cherimóia e de seu híbrido a atemóia. São Paulo: Nobel, 1999.182p.

CAUTIN, M. R.; RAZETO, B. Evaluación del comportamiento de yemas de chirimoyo sometidos a tratamientos de floración forzada. In: CONGRESO INTERNACIONALDEANONÁCEAS, 2., 1999, Chiapas. Memorias..., Chiapas: Universidad de Ciencias y Artes del Estado de Chiapas, 1999. p. 127-133.

DONADIO, L. C. Situação atual e perspectivas das anonáceas. In: SÃO JOSÉ, A. R.; SOUZA, I. V. B., MORAIS, O. M.; REBOUÇAS, T. N. H (Ed.). Anonáceas: produção e mercado (pinha, graviola, atemóia e cherimóia). Bahia: Universidade Estadual do Sudoeste da Bahia, 1997. p. 1-4.

KAVATI, R.; PIZA Jr., C. de T. Formação e manejo do pomar de fruta-doconde, atemóia e cherimólia. In: SÃO JOSÉ, A. R., SOUZA, I. V. B., MORAIS, O. M., REBOUÇAS, T. N. H (Ed.). Anonáceas: produção e mercado (pinha, graviola, atemóia e cherimólia). Bahia: Universidade Estadual do Sudoeste da Bahia, 1997. p. 75-83.

LEMOS, E. E. P. de, MARINHO, G. de A. Control of flowering in sugar apple (Annona squamosa L.) by leaf abscission for cropping out of season. In: CONGRESO INTERNACIONALDE ANONÁCEAS, 2., 1999, Chiapas. Memorias... Chiapas: Universidad de Ciencias y Artes del Estado de Chiapas, 1999. p. 251-255.

SÃO JOSÉ, A. R. Aspectos gerais das anonáceas no Brasil. In: SÃO JOSÉ, A. R., SOUZA, I. V. B., MORAIS, O. M.; REBOUÇAS, T. N. H (Ed.). Anonáceas: produção e mercado (pinha, graviola, atemóia e cherimólia). Bahia: Universidade Estadual do Sudoeste da Bahia, 1997.p. 5-6.

TAMAS, I. A. Hormonal regulation of apical dominance. In: DAVIES, P. J. (Ed.). Plant hormones and their role in plant growth and development. Dordrecht: Kluwer Academic Publishers, 1990. p. 393410. 